\title{
Ultra-low dose external beam radiotherapy for presumed choroidal lymphoma: a case report
}

\author{
Jeremy P. M. Flanagan ${ }^{1}$, Michael $\mathrm{Ng}^{2}$, Awet Z. Kibrom², Robin J. A. Filshie ${ }^{3}$, Richard J. Stawell ${ }^{4}$ and \\ Roderick F. O'Day ${ }^{4,5^{*}}$
}

\begin{abstract}
Primary choroidal lymphoma is a rare, slowly progressive intraocular malignancy. Most are low grade B cell lymphomas, often involving tissues adjacent to the choroid such as the subconjunctival space, lacrimal gland or orbit. Ideally, these lesions are biopsied to establish histopathological diagnosis. The most accessible ocular structure is biopsied. Obtaining tissue by transvitreal choroidal biopsy imparts a small but significant risk of ocular morbidity, including the need for multiple surgeries, retinal detachment and vision loss.

External beam radiotherapy (EBRT) is a common and effective treatment of low-grade lymphomas. EBRT has been found to very successfully treat primary marginal zone lymphomas of the ocular adnexa, which are typically of the same cell type as most primary choroid lymphomas. Ultra-low dose EBRT, most commonly using a total dose of 4 Gy, has been shown to be as effective as higher doses of radiotherapy for follicular or marginal zone lymphomas. The use of this low dose regimen for conjunctival lymphomas has been recently explored. The role of EBRT, and especially ultra-low dose EBRT, for treatment of primary choroidal lymphoma has been confined to case reports.

We describe a case of presumed primary choroidal lymphoma diagnosed on clinical findings alone as the risks of ocular biopsy were deemed too high, and report outcome following treatment with ultra-low dose EBRT.
\end{abstract}

\section{Introduction}

Primary choroidal lymphomas are rare malignancies that are often unilateral, without systemic involvement and of low-grade B cell type [1,2]. They usually present in patients over 60 years old with slowly-progressive unilateral vision loss, but may also be associated with eye pain or elevated intraocular pressure, or be entirely asymptomatic [1, 3]. Assessment of a biopsy specimen is used to establish the diagnosis, facilitate histological subtyping and direct treatment of these lesions [3]. When these lesions are confined to the choroid without involvement of the ocular surface, adnexa or orbit [3], lesion biopsy is performed by way of transvitreal fine-needle aspiration

\footnotetext{
* Correspondence: roderick.oday@gmail.com

${ }^{4}$ Royal Victorian Eye and Ear Hospital, Melbourne, Australia

${ }^{5}$ Centre for Eye Research Australia, University of Melbourne, Melbourne,

Australia

Full list of author information is available at the end of the article
}

(FNA). Transvitreal FNA carries a risk of iatrogenic complications, including retinal detachment, cataract and infection, and the potential for insufficient tissue sampling for diagnosis [1,4]. Transvitreal FNA biopsy rates of choroid tumours with cytologic non-diagnosis remains persistently high $[5,6]$, with up to half of all biopsies generating insufficient aspirates in thinner choroidal lesions [7-10].

There is no standardised treatment for primary choroidal lymphoma due to its rarity, however external beam radiotherapy (EBRT) has been shown to be an effective treatment with median doses of 30-36 Gy in 1.8-2Gy daily fractions $[1,3]$. Common complications at this radiation dose include dry eye, cataract and retinopathy $[3,11]$. Ultra-low dose radiotherapy (4 Gy dose delivered in $2 \times 2$ Gy fractions) has been found to successfully treat primary ocular adnexal lymphomas whilst minimizing side-effects [12-14]. This regimen has also been 
reported in patients with primary choroidal lymphoma recently [15-18]. However, in each of these recent case reports, diagnosis was confirmed by tissue biopsy. Although the risk of a significant complication is relatively low, patient and disease factors such as small volume disease and preserved visual function, may align such that treatment without tissue diagnosis is the preferred management plan. We describe a successful case of ultra-low dose EBRT for presumed choroidal lymphoma without tissue diagnosis.

\section{Case report}

A 73-year-old male with an ophthalmic history including ocular hypertension, allergic conjunctivitis, early cataracts and a family history of glaucoma was referred with unilateral, progressive choroidal infiltrate in his right eye 18 months after being found to have unilateral choroidal folds in the same eye. Aside from being a former smoker, past medical history was otherwise unremarkable and the patient denied any constitutional or B symptoms.

The patient was initially diagnosed with unilateral choroidal folds in his right eye by his ophthalmologist via enhanced-depth imaging optical coherence tomography (EDI-OCT; Heidelberg Spectralis, Heidelberg Engineering, Heidelberg, Germany; Fig. 1a), with right eye best corrected visual acuity (BCVA) 20/20 and left eye 20/16. After remaining stable for 11 months, right eye BCVA rapidly declined over a three-month period to $20 / 60$, due to progressive cataract and choroidal infiltrate. There was no clinical evidence of conjunctival, ocular adnexal or orbital involvement in either eye. There was no intraocular inflammation. A posterior subcapsular cataract had developed in the right eye and a pale choroidal infiltrate was now evident on slit-lamp examination, with increased choroidal thickening on EDI-OCT and overlying subretinal fluid (Fig. 1b, c). Right eye ocular ultrasound showed diffuse, hyperechoic choroidal thickening (Fig. 1d), no abnormality was apparent on right eye fundus autofluorescence imaging (Fig. 2a), and right eye pseudocolour imaging showed a hazy view of the fundus (Fig. 2b). A trial of oral high dose prednisolone $(75 \mathrm{mg})$ daily had no effect and was tapered after a month of no improvement in right BCVA or choroidal disease. The clinical and imaging features were highly suggestive of primary choroidal lymphoma. Vitreoretinal surgery review concluded that the potential ocular morbidity of a transvitreal choroidal biopsy were too high given the patient's relatively good vision and potentially low diagnostic yield.

Clinical review and systemic workup (full body positron emission tomography (PET), lumbar puncture, brain Magnetic Resonance Imaging (MRI) and bone marrow biopsy) by the haematologist did not detect
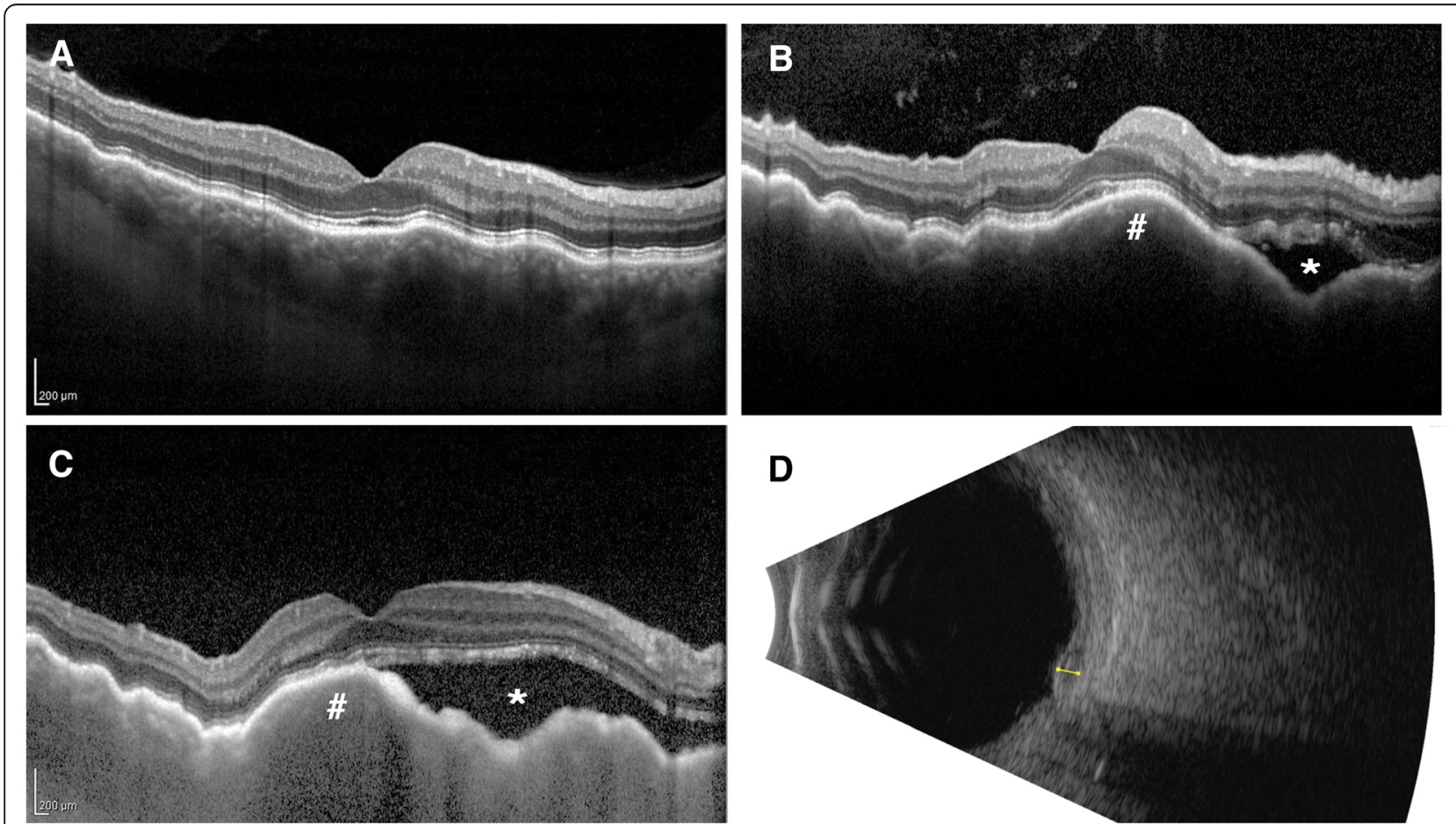

Fig. 1 EDI-OCT of patient prior to treatment initiation. a) EDI-OCT at initial diagnosis of choroid folds; $\mathbf{b})$ EDI-OCT following worsening of symptoms 11 months later; c) EDI-OCT on presentation to ophthalmology oncology clinic; $\mathbf{d}$ ) ocular ultrasound with yellow line showing lesion depth of $1.5 \mathrm{~mm}$. EDI-OCT = enhanced depth imaging optical coherence tomography' * = subretinal fluid; \# = choroidal lesion 

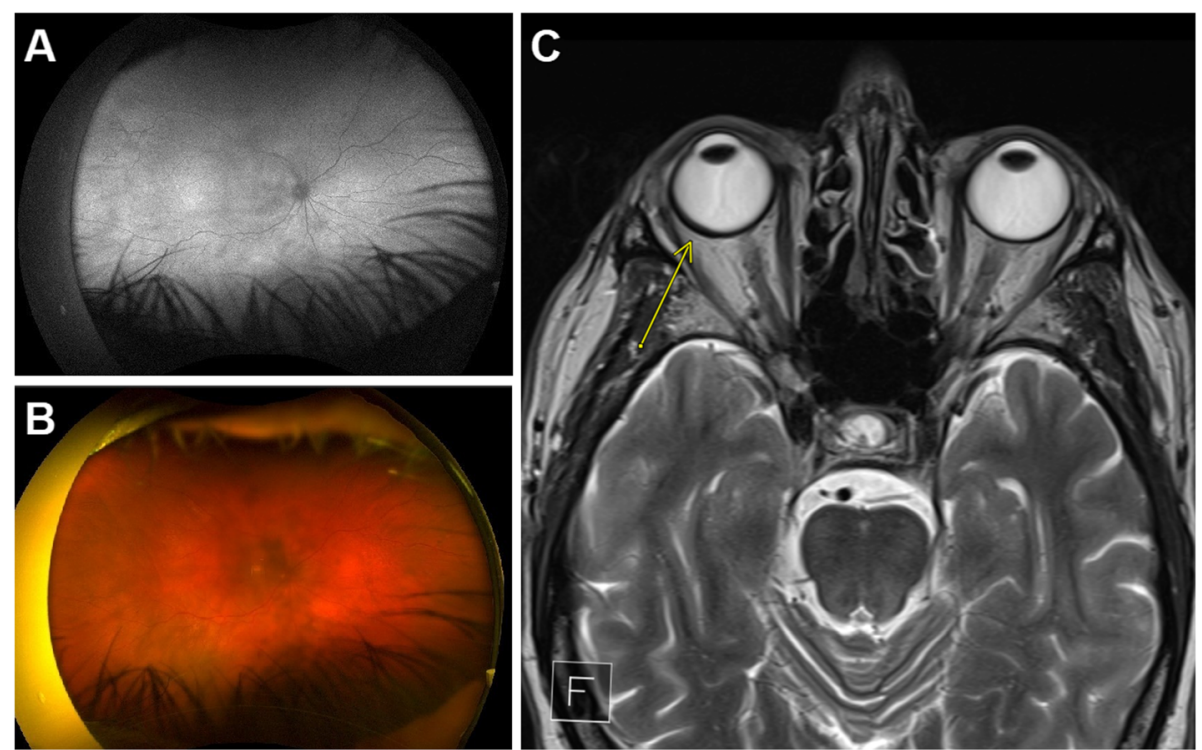

Fig. 2 Imaging prior to treatment initiation. Right eye a) fundus autofluorescence and b) pseudocolour images on presentation to ophthalmology oncology clinic; c) transverse orbital T2-weighted MRI image taken as part of systemic workup, with yellow arrow highlighting asymmetric thickening and enhancement of the wall of the right globe

locoregional or systemic disease, with brain MRI showing only a mild unilateral enhancement and thickening of the lateral wall of the right globe (Fig. 2c) and bone marrow biopsy showing low counts of two B cell clones in the bone marrow, the first being indicative of monoclonal B lymphocytosis and the second consistent with lymphoma.

A multidisciplinary team review, consisting of representatives from ophthalmology, haematology and radiation oncology, discussed management and it was decided to treat this patient with ultra-low dose EBRT for presumed right primary choroidal lymphoma without histological diagnosis. A total dose of $4 \mathrm{~Gy}$ to be delivered in 2 fractions on consecutive days to the entire orbit was recommended.

To ensure precise positioning, a radiotherapy immobilisation mask (Klarity Green ${ }^{\circ}$ Thermoplastic S-Type mask) was used for computerised tomography (CT) simulation and planning. The patient was positioned supine on the CT scanner couch, with anatomical landmarks and positioning lasers used to ensure patient and mask alignment. The CT scan was performed (Siemens Somatom Definition AS CT Scanner (Siemens AG, Munich, Germany)) with scan slice thickness of $2 \mathrm{~mm}$.

Target voluming on CT was performed using MIM Maestro $^{\circ}$ Version 6.8.9 (MIM Software Inc., Beachwood, $\mathrm{OH}, \mathrm{US})$. The clinical target volume (CTV) was the entire orbit, with a margin expansion of $3 \mathrm{~mm}$ to create the planning target volume (PTV). Pinnacle Treatment Planning System Version 3 (Philips, Fitchburg, WI, USA) was used to create an Intensity-modulated
Radiation Therapy (IMRT) plan. The IMRT plan consisted of a 5-beam arrangement at gantry angles of 15, 230, 265, 300 and 335 degrees, using 6MV energy photons as shown in Fig. 3. These beam arrangements were chosen to ensure conformal target coverage of the PTV and minimise exit dose to contralateral orbit. The plan was optimised to ICRU 83 guidelines [19] with the PTV receiving a minimum of $97.5 \%$ of the dose and a point maximum dose of $106.1 \%$, to a prescribed dose of $4 \mathrm{~Gy}$ in 2 fractions on consecutive days.

Treatment was commenced 1 day following simulation scan and delivered over consecutive days on the Elekta Versa HD linear accelerator with Agility Multi-Leaf Collimator (MLC). Image guidance utilized pre-treatment cone-beam computed tomography (CBCT) to ensure accurate delivery of radiation to the orbit. No side effects were reported during treatment.

Follow up 1 month after radiotherapy treatment revealed resolution of choroidal infiltrate on EDI-OCT, with right eye vision remaining reduced at 20/80 largely due to the posterior subcapsular cataract. Following right-sided cataract surgery 6 months later, right eye BCVA improved to 20/16. There was no clinical or EDIOCT evidence of disease recurrence at 6 or 12 months follow up (Fig. 4b, c) and right eye BCVA was stable at $20 / 16$.

\section{Discussion}

Primary indolent B cell lymphomas of the eye most frequently involve the ocular adnexa - the conjunctiva, lacrimal gland or orbit. Primary lesions solely involving the 

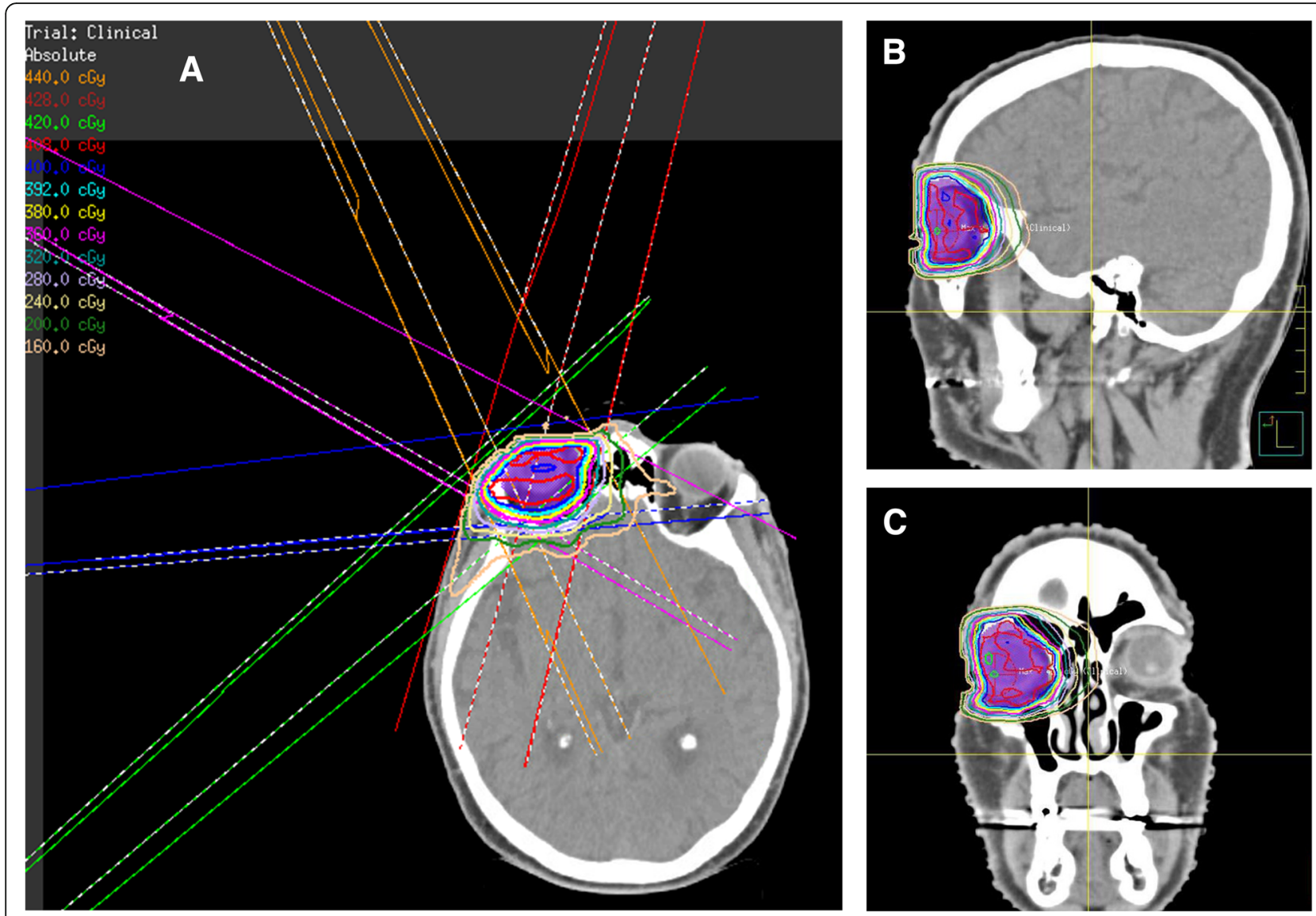

Fig. 3 Dose delivery and IMRT Beam Arrangement at $15^{\circ}, 230^{\circ}, 265^{\circ}, 300^{\circ}, 335^{\circ}$ : a) axial view; b) dose delivery, lateral view; c) dose delivery, coronal view. IMRT = intensity-modulated radiation therapy

choroid are extremely rare. Accordingly, much of the literature regarding treatment of these lesions is with reference to the ocular adnexa, rather than the uveal tract.

Indolent B cell lymphomas are particularly sensitive to radiotherapy. Moderate-dose EBRT (20-30 Gy delivered in $1.8-2$ Gy daily fractions) has been the gold-standard treatment for the last number of decades. B cell lymphomas of the ocular system have traditionally been treated with similar doses with consistently high rates of local control for lesions of the adnexa [20,21]. Treatment of
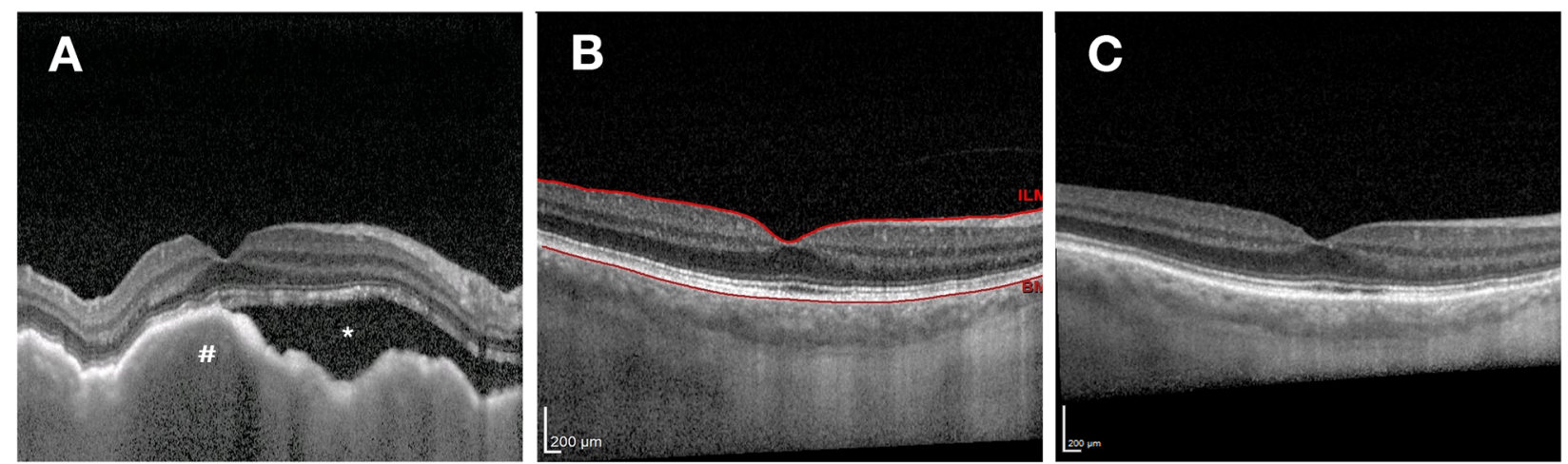

Fig. 4 EDI-OCT of right eye. (a) prior to radiotherapy; and b) 6 months following ultra-low dose EBRT and cataract surgery c) 12 months following ultra-low dose EBRT and cataract surgery. EDI-OCT = enhanced depth imaging optical coherence tomography; EBRT = External Beam Radiotherapy; ${ }^{*}=$ subretinal fluid; \# = choroidal lesion 
lesions of the choroid with similar EBRT doses (mean $30-36$ Gy in $1.8-2$ Gy daily fractions) has generated similar rates of tumour regression and local control, albeit with iatrogenic cataract, dry eye syndrome and decrease in BCVA being a common consequence of radiotherapy $[1,3]$. However, there has been increasing interest to reduce potential toxicity of lymphoma radiotherapy using lower doses. One randomized trial found no difference in disease response with standard dose (40-45 Gy) versus lower dose (24 Gy) for indolent systemic lymphomas [22] and another randomized trial in follicular and marginal zone lymphoma comparing 24 Gy versus 4 Gy doses showed slightly inferior local control with lower dose but less toxicity [23].

Ultra-low dose radiotherapy is an appropriate second line treatment option for lymphomas of the ocular system, given the desire to reduce potential long term radiotherapy complications, the unique radiosensitivity of these tumours and the ability to use re-irradiation with higher doses as a salvage option. Ultra-low dose EBRT has shown high rates of local control with lower rates of radiotherapy-induced complications in adnexal lesions [13, 24, 25], with 24-25 Gy reirradiation as an effective secondary intervention if tumours do not respond or progress following initial treatment [12]. In contrast, ultra-low dose radiotherapy for indolent B cell lymphomas of the choroid has been described only in a few recent case reports [15-18]. Details of these six cases are presented in Table 1 alongside our case for comparison.

Patients in these prior reports had poor BCVA in their affected eye, at 20/40 (1 case) 20/50 (3 cases) and only hand movements ( 2 cases). In contrast, our patient had relatively preserved vision at 20/60 and cataract consistent with this level of vision. Lesions in these cases were $2.9 \mathrm{~mm}, 1.9 \mathrm{~mm}, 4 \mathrm{~mm}$ and $7 \mathrm{~mm}$ in depth, with two studies not stating lesion depth at time of biopsy. In one case where disease was not responsive to initial ultralow dose EBRT at 5 weeks post-treatment, follow up treatment with 24 Gy in 12 fractions was delivered and associated with the resolution of both subretinal fluid and choroidal thickening [18].

In all prior cases diagnostic lesion biopsy was performed. Two were taken from involved structures located anterior to the choroid and four were transvitreal biopsies from the choroidal lesion by FNA, with or without parsplana vitrectomy (PPV), with minimal side effects reported. Although transvitreal choroidal biopsy is considered relatively safe with low risks of complications, it can be complicated by non-clearing vitreous hemorrhage requiring further surgery [9], cataract, retinal detachment and decreased BCVA at long-term follow up [26].

Our patient has a complete clinical response following a convenient two-day course of ultra-low dose radiotherapy, as early as 1 month following treatment without acute toxicity. Our treating team determined that ocular morbidity risk following chorioretinal biopsy outweighed potential diagnostic and treatment benefits. This took into account the high clinical suspicion that the diagnosis was primary choroidal lymphoma, the relatively preserved vision of the patient, a lack of other available biopsy sites (no adnexal involvement) and the low lesion thickness $(1.5 \mathrm{~mm})$ prior to treatment initiation. Although a recent study has demonstrated high diagnostic efficacy of FNA biopsy for smaller uveal tumours, the tumours in this study were still substantially thicker than the $1.5 \mathrm{~mm}$ lesion seen in our patient [27]. In our patient, choroidal infiltrate resolved rapidly following radiotherapy and has not recurred to date, and vision improved to 6/5 12 months after radiotherapy treatment and cataract surgery.

In conclusion, tissue diagnosis of ocular lesions is important to accurately identify lesion identity and dictate an appropriate course of treatment. The accepted standard of care for choroidal lymphoma remains EBRT of 20-30 Gy in consecutive $1.8-2$ Gy daily fractions. However, as we have presented in this case, in certain circumstances it may be better to treat complex patients with an ultra-low regimen dose based on presumptive diagnosis.

Table 1 Primary choroidal lymphomas treated with 2 × 2 Gy ultra-low-dose radiotherapy

\begin{tabular}{llllllll}
\hline Publication & Age & Eye & BCVA of affected eye & $\begin{array}{l}\text { Tumour depth at time } \\
\text { of biopsy } \mathbf{( m m )}\end{array}$ & Biopsy method & Follow up (months) & BCVA at follow up \\
\hline Shields et al. [15] & 67 & Right & $20 / 50$ & Unknown & FNA (adnexa) & 24 & $20 / 30$ \\
Yang et al. [16] & 64 & Left & $20 / 40$ & 2.9 & Unknown (adnexa) & 6 & $20 / 25$ \\
& 74 & Left & $20 / 50$ & 1.9 & FNA & 11 & $20 / 40$ \\
& 72 & Right & $20 / 50$ & 4.0 & FNA & 24 & $20 / 25$ \\
Dirani et al. [17] & 89 & Right & Hand motion & Unknown & 23-gauge PPV & 6 & Count fingers \\
Kam et al. [18] & 72 & Right & Hand motion & 7 & 27-gauge PPV & 3 & Count fingers \\
Our case & 73 & Right & 20/60 & 1.5 & NONE & 10 & $20 / 16$ (post-CSx) \\
& & & (with cataract) & & & & \\
\hline
\end{tabular}

$B C V A$ best corrected visual acuity, FNA Fine needle aspiration, $P P V$ pars-plana vitrectomy, CSx cataract surgery 


\section{Abbreviations}

EBRT: External beam radiotherapy; FNA: Fine-needle aspiration; EDIOCT: Enhanced-depth imaging optical coherence tomography; BCVA: Best corrected visual acuity; PET: Positron emission tomography; MRI: Magnetic resonance imaging; CT: Computerized tomography; CTV: Clinical target volume; IMRT: Intensity-modulated radiation therapy; MLC: Multi-Leaf Collimator; CBCT: Cone-beam computed tomography

\section{Acknowledgements}

Not applicable.

\section{Authors' contributions}

Data Collection: RFO, AZK, MN, RJS. Figures: JPMF. Literature search: JPMF, RFO, MN. Treatment: RFO, MN, RJF, AZK, RJAF. Manuscript Drafting: JPMF, RFO. Manuscript revision: RFO, MN, RJS, AZK, RJAF. All authors read and approved the final manuscript.

\section{Funding}

No funding was received for this study.

\section{Availability of data and materials}

Data sharing is not applicable to this study as no datasets were generated or analysed during the current study.

\section{Declarations}

\section{Ethics approval and consent to participate}

This study follows the tenets of the Declaration of Helsinki. Ethical approval was waived as it is a case report.

\section{Consent for publication}

Consent to publish the case report has been taken from the patient concerned and does not disclose the identity or infringe the privacy of the patient.

\section{Competing interests}

The authors declare that they have no competing interests.

\section{Author details}

${ }^{1}$ Ophthalmology, Department of Surgery, University of Melbourne, Melbourne, Australia. ${ }^{2}$ Department of Radiation Oncology, GenesisCare St Vincent's Hospital Melbourne, Melbourne, Australia. ${ }^{3}$ Department of Haematology, St Vincent's Hospital, Melbourne, Australia. ${ }^{4}$ Royal Victorian Eye and Ear Hospital, Melbourne, Australia. ${ }^{5}$ Centre for Eye Research Australia, University of Melbourne, Melbourne, Australia.

Received: 7 September 2021 Accepted: 17 February 2022

Published online: 05 March 2022

\section{References}

1. Aronow ME, Portell CA, Sweetenham JW, Singh AD (2014) Uveal lymphoma: clinical features, diagnostic studies, treatment selection, and outcomes. Ophthalmology 121(1):334-341. https://doi.org/10.1016/j.ophtha.2013.09.004

2. Hwang CS, Yeh S, Bergstrom CS (2014) Diagnostic vitrectomy for primary intraocular lymphoma: when, why, how? Int Ophthalmol Clin 54(2):155-171. https://doi.org/10.1097/iio.0000000000000022

3. Mashayekhi A, Hasanreisoglu M, Shields CL, Shields JA (2016) EXTERNAL BEAM RADIATION FOR CHOROIDAL LYMPHOMA: efficacy and complications. Retina 36(10):2006-2012. https://doi.org/10.1097/iae.0000000000001026

4. Mastropasqua R, Thaung C, Pavesio C, Lightman S, Westcott M, Okhravi N, Aylward W, Charteris D, da Cruz L (2015) The role of Chorioretinal biopsy in the diagnosis of intraocular lymphoma. Am J Ophthalmol 160(6):1127-1132. e1121. https://doi.org/10.1016/j.ajo.2015.08.033

5. Corrêa ZM, Augsburger JJ (2019) Indications for fine needle aspiration biopsy of posterior segment intraocular tumors. Am J Ophthalmol 207:4561. https://doi.org/10.1016/j.ajo.2019.05.018

6. Wang M, Levy G, Qin X, Adeniran AJ, Cai G (2021) Fine-needle aspiration biopsy of intraocular mass-like lesions: impact of rapid on-site evaluation, Repeated Biopsy and Ancillary Immunocytochemistry. Am J Clin Pathol 156(2):268-277. https://doi.org/10.1093/ajcp/aqaa235
7. Augsburger JJ, Corrêa ZM, Schneider S, Yassin RS, Robinson-Smith T, Ehya H, Trichopoulos N (2002) Diagnostic transvitreal fine-needle aspiration biopsy of small melanocytic choroidal tumors in nevus versus melanoma category. Trans Am Ophthalmol Soc 100:225-232 discussion 232-224

8. Cohen VM, Dinakaran S, Parsons MA, Rennie IG (2001) Transvitreal fine needle aspiration biopsy: the influence of intraocular lesion size on diagnostic biopsy result. Eye (Lond) 15(Pt 2):143-147. https://doi.org/10.103 8/eye.2001.48

9. Seider MI, Berry DE, Schefler AC, Materin M, Stinnett S, Mruthyunjaya P (2020) Multi-center analysis of intraocular biopsy technique and outcomes for uveal melanoma: ocular oncology study consortium report 4. Graefes Arch Clin Exp Ophthalmol 258(2):427-435. https://doi.org/10.1007/s00417-01 9-04531-8

10. McCannel TA, Chang MY, Burgess BL (2012) Multi-year follow-up of fineneedle aspiration biopsy in choroidal melanoma. Ophthalmology 119(3): 606-610. https://doi.org/10.1016/j.ophtha.2011.08.046

11. Berenbom A, Davila RM, Lin HS, Harbour JW (2007) Treatment outcomes for primary intraocular lymphoma: implications for external beam radiotherapy. Eye (Lond) 21(9):1198-1201. https://doi.org/10.1038/sj.eye.6702437

12. Deantonio L, Pinnix CC, Tsang R (2020) Radiation therapy of extranodal marginal zone lymphomas. Ann Lymphoma 4. https://doi.org/10.21037/a ol-20-23

13. Pinnix CC, Dabaja BS, Milgrom SA, Smith GL, Abou Z, Nastoupil L, Romaguera J, Turturro F, Fowler N, Fayad L, Westin J, Neelapu S, Fanale MA, Rodriguez MA, Hagemeister F, Lee HJ, Oki Y, Wang M, Samaniego F, Chi L, Esmaeli B (2017) Ultra-low-dose radiotherapy for definitive management of ocular adnexal B-cell lymphoma. Head Neck 39(6):1095-1100. https://doi. org/10.1002/hed.24717

14. Lee Gl, Oh D, Kim WS, Kim SJ, Ko YH, Woo Kl, Kim YD, Ahn YC (2018) Lowdose radiation therapy for primary conjunctival marginal zone B-cell lymphoma. Cancer Res Treat 50(2):575-581. https://doi.org/10.4143/crt.201 7.182

15. Shields JA, Dockery PW, Shields CL (2021) Boom-boom radiotherapy for choroidal lymphoma-two days and done. Ophthalmol Retina 5(1):15. https://doi.org/10.1016/j.oret.2020.09.002

16. Yang X, Dalvin LA, Lim LS, Mashayekhi A, Shields JA, Shields CL (2021) Ultralow-dose (boom-boom) radiotherapy for choroidal lymphoma in three consecutive cases. Eur J Ophthalmol 31(2):Np91-np96. https://doi.org/10.11 77/1120672119888985

17. Dirani A, Allaire G, Callejo S, Belair ML, Biernacki K, Corriveau C, Hammamji K (2017) Choroidal extranodal marginal zone lymphoma diagnosed by fullthickness retinochoroidal biopsy: case report and review of the literature. Int Med Case Rep J 10:153-158. https://doi.org/10.2147/imcrj.S129171

18. Kam AW, Galvin J, Cherepanoff S, Miller AA, Fung AT (2019) Primary choroidal lymphoma diagnosed with 27-gauge pars Plana vitrectomy choroidal biopsy. Case Rep Ophthalmol 10(2):213-220. https://doi.org/10.11 $59 / 000500238$

19. ICRU (2010) Prescribing, Recording, and Reporting Photon-Beam IntensityModulated Radiation Therapy (IMRT). ICRU Report 83 . J ICRU 10(1):3-106. https://doi.org/10.1093/jicru_ndq004

20. Tanenbaum RE, Galor A, Dubovy SR, Karp CL (2019) Classification, diagnosis, and management of conjunctival lymphoma. Eye Vis (Lond) 6(1):22-22. https://doi.org/10.1186/s40662-019-0146-1

21. Platt S, Al Zahrani Y, Singh N, Hill B, Cherian S, Singh AD (2017) Extranodal marginal zone lymphoma of ocular adnexa: outcomes following radiation therapy. Ocular Oncol Pathol 3(3):181-187. https:/doi.org/10.1159/000453615

22. Lowry L, Smith P, Qian W, Falk S, Benstead K, Illidge T, Linch D, Robinson M, Jack A, Hoskin P (2011) Reduced dose radiotherapy for local control in nonHodgkin lymphoma: a randomised phase III trial. Radiother Oncol 100(1):8692. https://doi.org/10.1016/j.radonc.2011.05.013

23. Hoskin P, Popova B, Schofield O, Brammer C, Robinson M, Brunt AM, Madhavan K, Illidge T, Gallop-Evans E, Syndikus I, Clifton-Hadley L, Kirkwood AA (2021) 4 Gy versus 24 Gy radiotherapy for follicular and marginal zone lymphoma (FoRT): long-term follow-up of a multicentre, randomised, phase 3, non-inferiority trial. Lancet Oncol 22(3):332-340. https://doi.org/10.1016/ s1470-2045(20)30686-0

24. Saleh K, Michot JM, Schernberg A, Lazarovici J, Chahine C, Danu A, KhalifeSaleh N, Rossignol J, Ghez D, Martin V, Mazeron R, Fermé C, Boros A, Ribrag $V$, Girinsky T (2020) Repeated courses of low-dose $2 \times 2$ Gy radiation therapy in patients with indolent B-cell non-Hodgkin lymphomas. Cancer Med 9(11):3725-3732. https://doi.org/10.1002/cam4.2796 
25. König L, Hörner-Rieber J, Bernhardt D, Hommertgen A, Rieken S, Debus J, Herfarth K (2018) Response rates and recurrence patterns after low-dose radiotherapy with $4 \mathrm{~Gy}$ in patients with low-grade lymphomas. Strahlenther Onkol 194(5):454-461. https://doi.org/10.1007/s00066-018-1277-3

26. Bagger M, Tebering JF, Kiilgaard JF (2013) The ocular consequences and applicability of minimally invasive 25 -gauge transvitreal retinochoroidal biopsy. Ophthalmology 120(12):2565-2572. https://doi.org/10.1016/j. ophtha.2013.07.043

27. Kim RS, Chevez-Barrios P, Divatia M, Bretana ME, Teh B, Schefler AC (2018) Yield, techniques, and complications of Transvitreal and Transscleral biopsies in small uveal melanoma. JAMA Ophthalmol 136(5):482-488. https://doi. org/10.1001/jamaophthalmol.2018.0561

\section{Publisher's Note}

Springer Nature remains neutral with regard to jurisdictional claims in published maps and institutional affiliations.

\section{Submit your manuscript to a SpringerOpen ${ }^{\circ}$ journal and benefit from:}

- Convenient online submission

- Rigorous peer review

- Open access: articles freely available online

High visibility within the field

- Retaining the copyright to your article

Submit your next manuscript at $\boldsymbol{\nabla}$ springeropen.com 